\title{
Performance-Determining Coordinative and Conditional Abilities in the Fire Brigade Sport Discipline "100 m Obstacle Course" within Elite
} Female Athletes

\author{
Sophia Lichan, Robert Prill* and Sven Michel
}

Department for Therapy Sciences II, Brandenburg University of Technology Cottbus, Germany

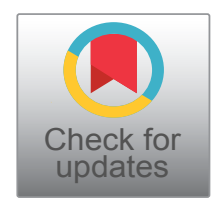

*Corresponding author: Dr. Robert Prill, Brandenburg University of Technology Cottbus - Senftenberg, Department for Therapy Sciences II, Universitätsplatz 1, 01968 Senftenberg, Germany, Tel: +49-3573-85710, Fax: +49-3573-85700

\begin{abstract}
Background: Fire brigade sport is a common sport in parts of Europe, with a growing body of popularity. In sports science, no research has been carried out in this field up to date. In consequence, there are no structures for talent scouting in firefighting sports. "100 m obstacle course" is one out of the four disciplines in this sport. For an efficient scouting of talents and training in general the necessary conditional and coordinative abilities must be identified. Dynamic balance, short sprint and motor differentiation ability seem to be promising abilities for determining completion performance.
\end{abstract}

Methods: In 16 elite female fire brigade athletes the Purdue Pegboard Test for motor differentiation ability, a $23 \mathrm{~m}$ sprint for basic speed and Backward balancing, representing dynamic balance, were performed. Those results were correlated to the completion performance of those athletes to identify the highest influencing factors on performance in this discipline.

Results: The testing of the $23 \mathrm{~m}$ sprint shows the strongest correlation coefficient with $r=0.81$. The dynamic balance ability shows a correlation of $r=0.63$. Little correlation was observed to the motor differentiation ability $(r=0.18)$.

Conclusion: A first step was made in identifying necessary abilities for improving performance in the " $100 \mathrm{~m}$ obstacle course" and thus for a performance structure in fire brigade sports. Basic sprint abilities seem to be the most influencing factor on competition performance.

\section{Keywords}

Fire fighter sport, Fire brigade sport, Conditional abilities, Talent scouting

\section{Introduction}

Fire brigade sport is a common sport in parts of Europe, with a growing body of popularity. The sport represents a team sport, consisting of two team disciplines and two individual disciplines. The team disciplines are the "extinguishing attack" and a " $4 \times 100$ m relay". The individual disciplines are the "hook ladder climbing" and the "100 m obstacle course", from which a duel classification results. In the last three disciplines there are differences in the obstacles between men and women [1]. In sports science, no research has been carried out in this field up to date. In consequence, there are no structures for talent scouting in firefighting sports. In other areas, such as football and athletics, junior competitions are still the means of choice for talent selection [2]. Some publications have shown that this methodology is not a satisfactory criterion for predicting future excellence [3-6]. We have the opinion, that talent selection in the form of junior competitions is not sufficient to ensure top performances in the career progresses of the athletes. It can be deduced from this that for an adequate talent scouting all performance prerequisites of an athlete have to be considered. To this end, it is useful to create a performance structure as already developed for some sports. This provides insights in the performance requirements of athletes for the respective sport [7]. All abilities and skills must be taken into account here.

There is currently a cooperation project on this subject between the German Sports Aid Foundation, the 
German Sports Association (DOSB), the German Boxing Association (DBV), the German Swimming Association (DSV), the German Ice Speed Association (DESG) and the Institute for Applied Training Science (IAT) called "Germany promotes talent" (DELTA for short). The goal of the project is the creation of an athlete profile with the consideration of all performance requirements for the sports boxing, speed skating and swimming. The following factors are considered: Competition performance, conditional performance prerequisites, technical and coordinative performance prerequisites, psychological performance prerequisites, the athlete's resilience, constitution and an overall assessment of the top sports potential [8]. Based on the athlete profile, a performance structure in the sport can be developed and an improved talent scouting could take place in fire brigade sport as well.

On the basis of this missing performance structure, all performance requirements in firefighting sport must be examined. The categorization of the performance prerequisites, as used in the project "DELTA", can be used as a basis. The aim of this study is to gain first insights in the field of conditional and coordinative performance prerequisites. At this point we specialize in in the discipline "100 m obstacle course". First the relevance of the two mentioned performance factors is examined by correlating to the individual competition performance. In the present study, due to the differences between women and men in the discipline, the focus was set on female firefighters.

As to be seen in Figure 1 there is a complex track to be completed. To successfully complete the discipline, the athlete must overcome various obstacles and exercises as quickly as possible. The start takes place from a starting block. After $23 \mathrm{~m}$ the women have to overcome a hurdle. This is $68-72 \mathrm{~cm}$ high and $1.20 \mathrm{~m}$ wide. Five metres after the obstacle there are two rolled up target tubes, each of which must weigh at least $2.0 \mathrm{~kg}$. The two tubes are picked up by the athlete in the sprint. Ten meters after the hose is picked up, there is a running bar (length: $8 \mathrm{~m}$, height: $80 \mathrm{~cm}$, width: $18 \mathrm{~cm}$ ) which is crossed. After a total of $75 \mathrm{~m}$ there is a distributor. On the way between the running beam outlet and the distributor the athlete couples the middle coupling of the two hoses together, then one coupling is attached to the distributor and the other to the jet pipe, which is located in the belt coupling of the athlete [9].

\section{Methods}

As a result of the lack of preliminary investigations, the topic was first approached by theoretical basics of sports science. The first step was an analysis of the performance-determining coordinative abilities in the discipline. Theoretical basics were the concept of the coordinative abilities of Schnabel and Meinel $[10,11]$. In order to include the relation of the temporal component of the time pressure in the execution of the coordinative abilities, a model by Zimmermann with the "ability for coordination under time pressure" was included [12]. The analysis showed that the three performancedetermining abilities are the coupling ability, the motor differentiation ability in expressing the of the hands and fingers as well as the dynamic balance ability, which are called up in each case under time pressure. For the objective, the investigation on the relevance of these abilities, we lean on existing adequate test procedures. However, no adequate test procedure for testing the coupling ability was found in the literature. Accordingly, only motor differentiation ability and dynamic balance ability were tested in the analysis. Motor differentiation ability is explained as "the ability to achieve a high degree of fine tuning of individual movement phases and partial body movements, which is expressed in great movement accuracy and movement economy" [12]. The ability can be classified into four different types [13]. In this theory, the exactness of the movement execution, various movement parameters, primarily acting body parts as well as external factors are considered. It is assumed that the motor differentiation ability is of high relevance in the discipline "100 m obstacle course" once with the hose admission and coupling distance. In those phases, it is very important that the movements are carried out with maximum precision by the hands

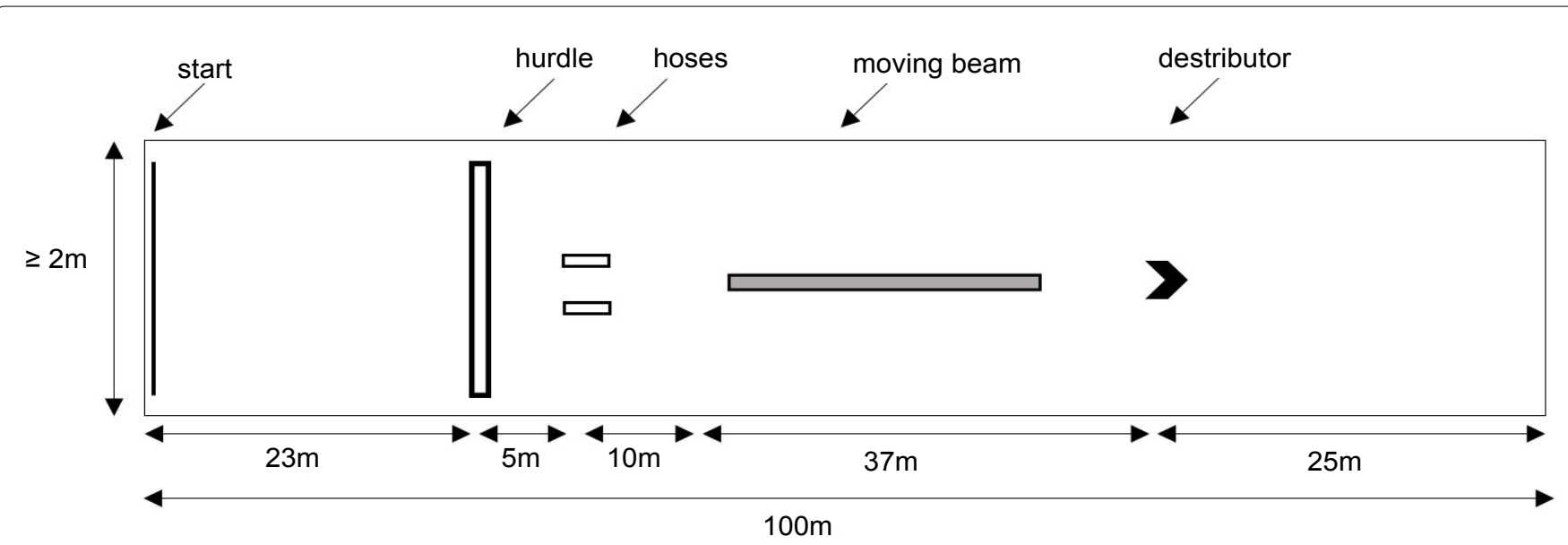

Figure 1: 100 m obstacle course track draft. 
and fingers in order to grip or join the clutches clearly together. Thus the dexterity of the hands and fingers, being the major acting body parts in the movement phases, is assumed to be a performance determining ability. The ability can be measured on the basis of various forms of execution of the different phases of the target movement, partial body movement as well as the the movement in general. It must be measured in relation to space, time and dynamics. Consequently, the test used here examines the dexterity of the hands and fingers of the test persons. In the process not all elements of the classification according from Kircheis can be considered. In the study the type of motion parameters with the time factor of the time pressure during the execution of motion coordination and the type of motion execution in accuracy as well as control of motion speed shall be tested. The "Purdue Pegboard
Test" is used as the basis for the test, which analyses the bimanual as well as manual dexterity of the hands and fingers $[14,15]$. The test consists of a board with holes and matching pins. The test subjects had the task in the order in which the ability in the discipline is required to place the pins in the corresponding holes. As a result, the subjects first simultaneously placed the pins twice in a row with both hands into two opposite holes, then only with the right hand into the underlying hole on the right side, and finally once two opposite holes simultaneously with both hands. The test persons independently stopped the time they needed with a tablet.

The balance ability describes to what extent a test person is able to "keep his whole body in a state of balance or to maintain or restore this situation during and after extensive body displacements" [12]. The ability

Filling in the questionnaires

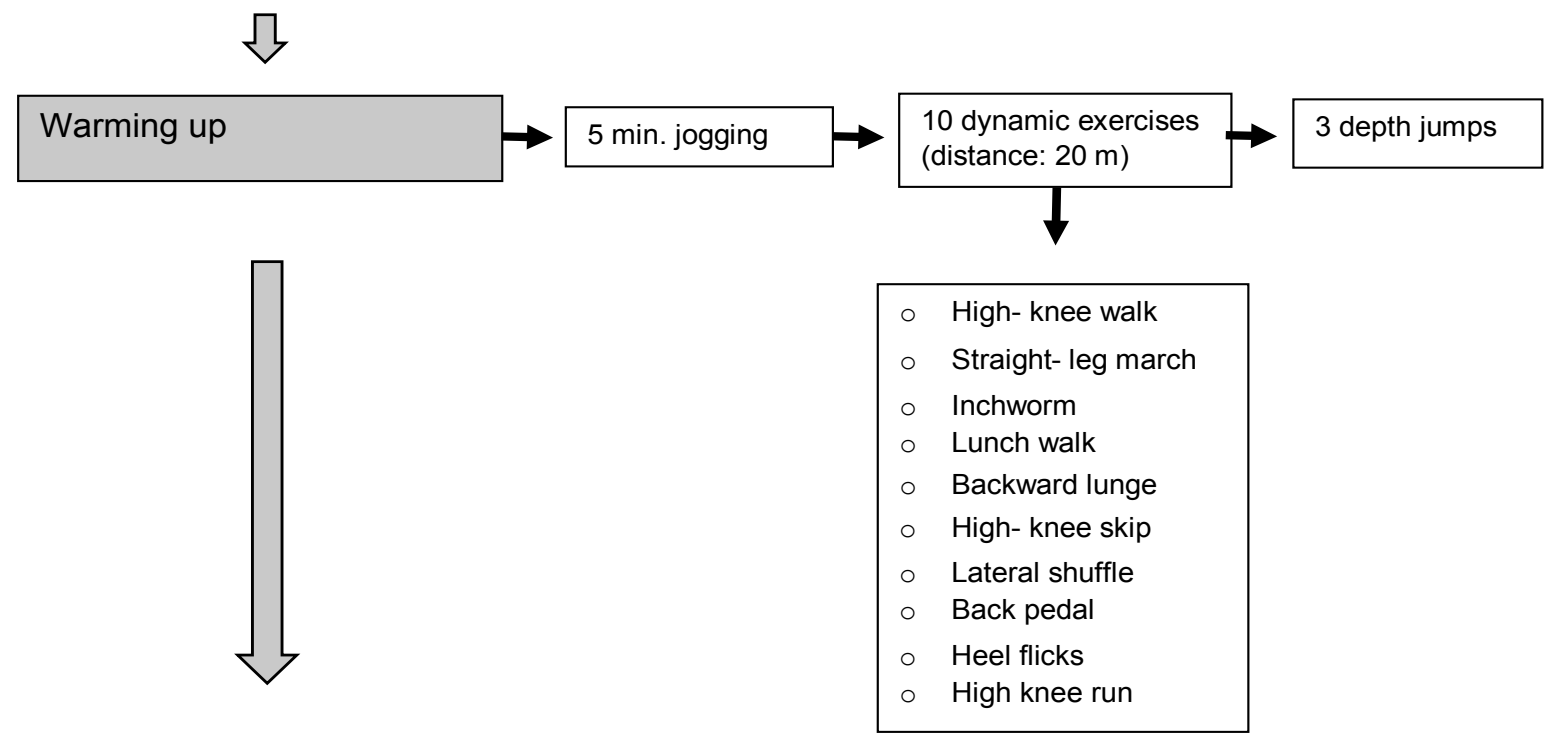

Testing conditional ability (basic speed)

$23 \mathrm{~m}$ sprint $\rightarrow 6 \mathrm{~min}$. break

$23 \mathrm{~m}$ sprint

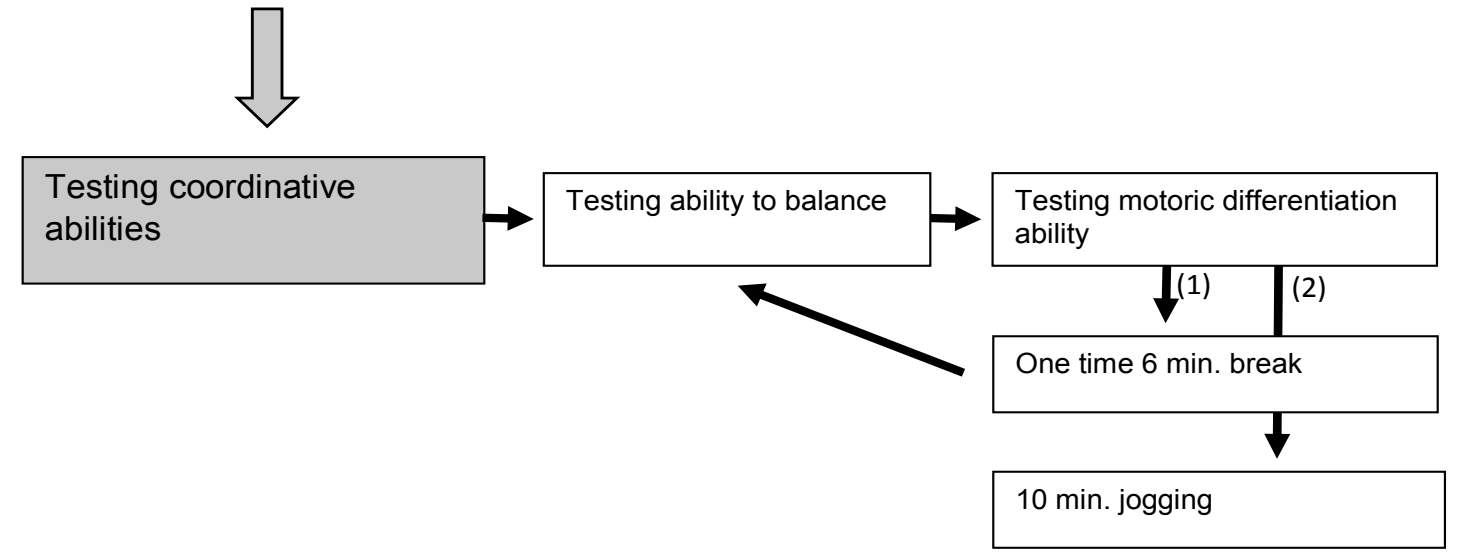

Figure 2: Test procedure. 
is divided into dynamic and static balance ability. In the discipline "100 m obstacle course" it is assumed that the dynamic balance ability is the performance determining ability by overflowing the moving beam. The test "Backward balancing" was used to test the dynamic balance ability. In the original test, the test persons have the task of balancing backwards in a tandem gear over three beams of different widths without touching the ground. Based on the test the subjects have to cross a gymnastic bar (length: $4 \mathrm{~m}$, height: $35 \mathrm{~cm}$, width: 10 $\mathrm{cm}$ ) backwards in a tandem gear as fast as possible. $1 \mathrm{~m}$ before and $1 \mathrm{~m}$ after the bar the time is measured with a time barrier.

The following approach was used to investigate the conditional performance requirements. The discipline "100 m obstacle course" consists of a $100 \mathrm{~m}$ sprint, which alone represents a cyclic movement. However, the sprint in the discipline is interrupted from the first obstacle by acyclic movements, whereby the coordinative abilities are demanded from the athletes under time pressure. For this reason, only the first 23 $\mathrm{m}$ represent a pure sprint as a cyclic movement. Ikai already showed that an athlete in this is determined by basic speed [16]. As a result, it is assumed in the present study that basic speed is one of the conditional factors determining performance. For the investigation, a 23 $\mathrm{m}$ sprint from the starting block is performed with an acoustic start signal. Analogous to testing coordinative capabilities, the test was performed twice, using the best time as the examination parameter. The following examination procedure was chosen for the tests, which is shown in Figure 2. In order to determine the relevance of the assumed performance-determining coordinative and conditional abilities in the discipline " $100 \mathrm{~m}$ obstacle course" of the women, the results of these tests were correlated with the best performances in competition of the fire fighters. The Bravais-Pearson correlation coefficient $(r)$ was used. The calculation initially revealed the presence of a monotonous relationship of the same or opposite sense. Furthermore, in the case of a monotonous correlation with the same sense, it was determined whether this was in a weak, medium or strong range $[17,18]$. The results of the best competition performances are published on www.feuerwehrsportstatistik.de. For additional impressions have a look on Appendix Figure 1 and Appendix Figure 2.

Inclusion criteria for participants were to be a female firefighter athlete from the Brandenburg county selection team. In addition, the test subjects should practice firefighting sports for at least five years in order to be able to ensure a sufficiently high level of coordination skills for testing $[19,20]$. Exclusion criteria were according to the recommendations of McGee a diagnosed ligament injury in the last twelve months, diagnosed bone, tendon or muscle injuries in the last six months, significant changes in training intensity and methodology in the last six weeks, cardiovascular diseases, systemic diseases or other performancelimiting diseases [21].

Finally, 16 athletes with an average age of 24

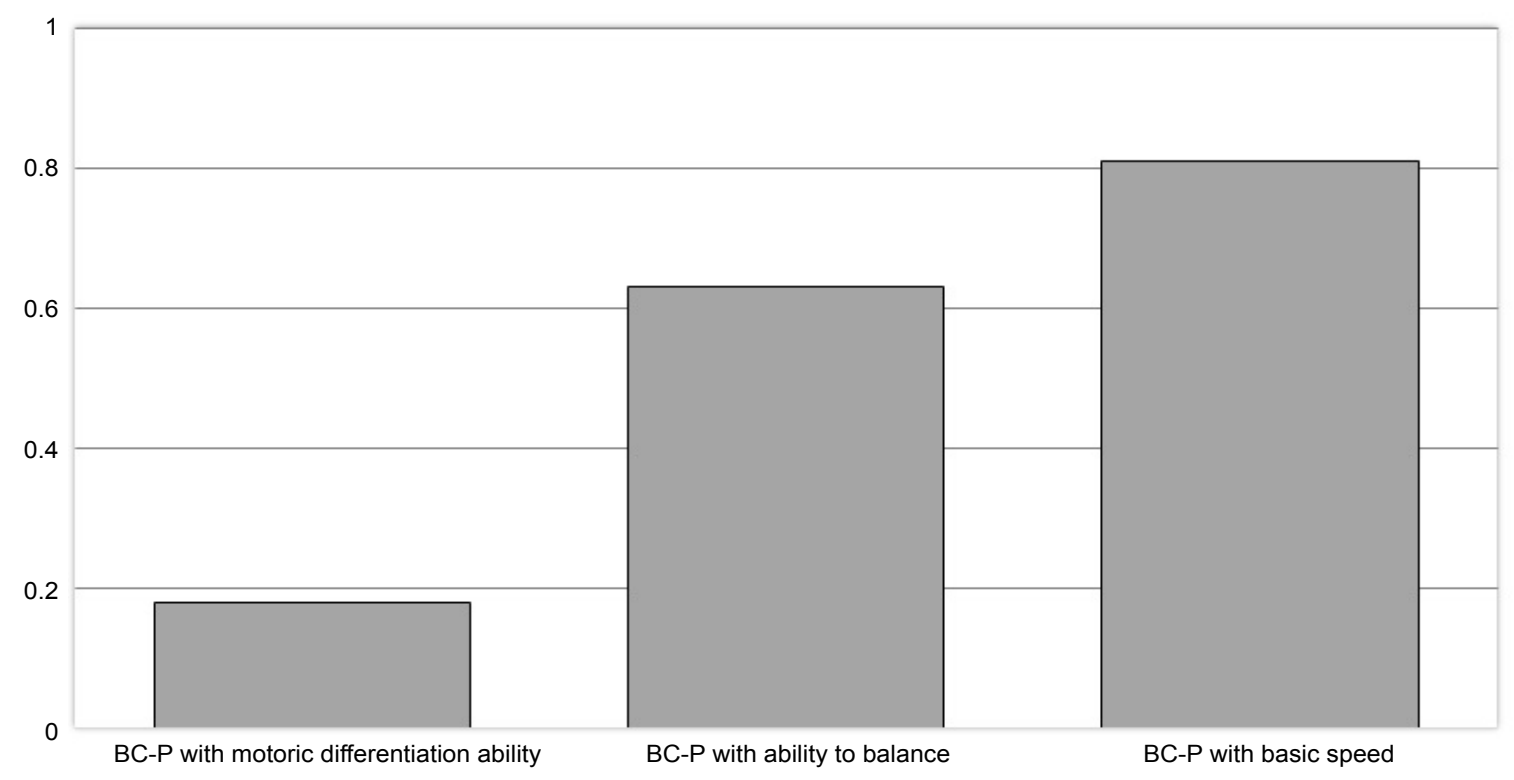

Figure 3: The correlation between best competition performance and motor skills. 
participated. They have been training firefighter sports in average for eleven years.

\section{Results}

The performance in competition of the test persons of the discipline "100 m obstacle course" is $20.58 \mathrm{~s}$ $\pm 1.39 \mathrm{~s}$ in average. The fastest time is $18.68 \mathrm{~s}$ and the slowest time $23.87 \mathrm{~s}$. This results in a span (d) of 5.19s. When testing the motor differentiation ability, the test persons require an average of $8.70 \mathrm{~s} \pm 1.00 \mathrm{~s}$. The fastest test result is $7.29 \mathrm{~s}$ and the slowest is $10.50 \mathrm{~s}$. This results in a range of $3.21 \mathrm{~s}$ for the test results. When testing the dynamic balance ability, the test persons required an average of $11.30 \mathrm{~s} \pm 1.50 \mathrm{~s}$. The minimum of the values and thus the fastest time is $9.50 \mathrm{~s}$. The maximum is $14.28 \mathrm{~s}$. The span is $4.78 \mathrm{~s}$. The test persons needed an average of $4.47 \mathrm{~s} \pm 0.26 \mathrm{~s}$ for running the " $23 \mathrm{~m}$ Sprint". The fastest time was $4.23 \mathrm{~s}$ and the slowest time $5.30 \mathrm{~s}$. The range (d) between the fastest and slowest time is 1.07s. As shown in Figure 3 all test procedures for the presumed performance-determining coordinative and conditional abilities are in a monotonous, unidirectional relationship with the best competition performances of the test persons. The testing of the $23 \mathrm{~m}$ sprint shows the strongest correlation coefficient with $r=0.81$. The dynamic balance ability shows a correlation of $r=$ 0.63. At least the test of motor differentiation ability correlates with the competition best performance of the test persons. The result was a correlation of $r=0.18$. In summary, all results are presented in Table 1.

\section{Discussion}

The importance of the coordinative and conditional performance prerequisites for the discipline "100 m obstacle course" was clearly demonstrated by the investigations as well as theoretical introductions. A relevance for the performed tests and selected abilities could was shown. According to the calculations, basic speed is the most important, followed by dynamic balance ability and with few relevance motor differentiation abilities. At this point it should be mentioned that the $23 \mathrm{~m}$ sprint test was the only test that is exactly replicates a task performed in the "100 m obstacle course". This can be a reason for the high correlation. Despite that first statements can be made for the production of a performance structure in the fire-brigade sport. The development of a complete performance structure in the discipline " $100 \mathrm{~m}$ obstacle course" requires additional investigations on this topic. So far only assumptions and considerations can be made, which represent the basis for further research. The following aspects, not beeing considered in the present study, should be investigated for more insights in the discipline: anthropometric data, environmental conditions, mental performance requirements and the resilience of the athletes $[22,23]$.

The knowledge acquired about the respective relevance of the coordinative and conditional abilities can also be used in various phases of child and youth training. Above all, between the ages of 4 and 5 and between the ages of nine and ten, children should gain as much exercise experience as possible during training. In this stage of life, especially coordinative skills are collected and developed in a variety of ways in order to create a broad basis for motor learning. This is the basis for the later movement accuracy as well as control ability. Only after the 10 year of life does the sport specific training begin and first competition experiences. Despite the beginning specializations of the respective sports, the training remains the variety of the coordinative skills. This makes it possible for athletes between the ages of $12^{\text {th }}$ and $14^{\text {th }}$ to change to another sport in a performance-oriented way due to a athlete profile that is not optimal for the sport. After the age of 14, the beginning of an in-depth technical specific training, consisting of conditional factors, which are individually adapted to the sport, is reached. In addition, special technical movement sequences are trained [24]. Thus, the knowledge of this study can be included in the training planning. Based on the order in which training is structured in children and adolescents, a first athlete profile should be created by the age of 10 at the latest for athletes who are qualified for a performanceoriented deepening of a sport. Thus the athletes can be assigned to the respective performance structures of the sports on the basis of the athlete profiles. The next preparation of the athlete's performance prerequisites should take place in the course of the $12^{\text {th }}-14^{\text {th }}$ year of life in order to be able to check once again whether the athlete still has good performance prerequisites for the sport. Should this not be the case, the athlete would have the option of being able to change the sport in a performance-oriented way during this phase of his life. For an overview of the development of athletes,

Table 1: Results.

\begin{tabular}{|l|l|l|l|l|l|}
\hline & $\begin{array}{l}\text { Fastest } \\
\text { time }\end{array}$ & $\begin{array}{l}\text { Slowest } \\
\text { time }\end{array}$ & $\begin{array}{l}\text { Span between fastest } \\
\text { and slowest time }\end{array}$ & Average & r \\
\hline $\begin{array}{l}\text { Performance in competition "100 m } \\
\text { obstacle course" }\end{array}$ & $18.68 \mathrm{~s}$ & $23.87 \mathrm{~s}$ & $5.19 \mathrm{~s}$ & $20.58 \mathrm{~s} \pm 1.39 \mathrm{~s}$ & 1.00 \\
\hline $\begin{array}{l}\text { Testing of motor differentiation ability } \\
\text { Testing of dynamic balance ability }\end{array}$ & $7.29 \mathrm{~s}$ & $10.50 \mathrm{~s}$ & $3.21 \mathrm{~s}$ & $8.70 \mathrm{~s} \pm 1.00 \mathrm{~s}$ & 0.18 \\
\hline Testing of "23 m Sprint" & $9.50 \mathrm{~s}$ & $14.28 \mathrm{~s}$ & $4.78 \mathrm{~s}$ & $11.30 \mathrm{~s} \pm 1.50 \mathrm{~s}$ & 0.63 \\
\hline
\end{tabular}

$r=$ correlation coefficient between competition performances and test results of coordinative and conditional abilities. 
the performance of the athletes should be recorded at regular intervals. This should be done by establishing a complete uniform athlete profile.

\section{Appendix}

Appendix Figure 1 and Appendix Figure 2 showing the $100 \mathrm{~m}$ obstacle course.

\section{References}

1. Grosche C (2013) Team MV- Feuerwehrsport.

2. Martindale R, Collins D, Daubney J (2005) Talent: Development: A Guide for Practice and Research Within Sport. National Association for Physical Education in Higher Education 57: 353-375.

3. Bloom B (1985) Developing talent in young people. New York: Ballantine.

4. Côté I, Lidor R, Hackfort D (2009) Seven postulates about youth sport activities that lead to continued participation and elite performance. International Journal of Sport and Exercise Psychology 7: 7-17.

5. Gulbin J, Oldenziel K, Weissensteiner J, Gagné F (2010) A look through the rear view mirror: Developmental experiences systems. Talent Development and Excellences 2: $149-164$.

6. Hoffmann A, Wulff J (2013) Junior success-The way to the top? Barcelona: Unifying Sport Science- 18th annual Congress of the ECSS.

7. Schnabel G (1981) Leistungsstruktur, Trainingsstruktur und ihr Zusammenhang 2. Teil. Medizin und Sport 21: 318-320.

8. Wulff J, Walter N, Fudel R, Altmann K, Hoffmann A (2014) DELTA Deutschland entwickelt Talente- Projektbeschreibung. Leipzig: Institut für Angewandte Trainingswissenschaft, Fachbereich Nachwuchsleistungssport.

9. Limbach G (2014) Feuerwehrsport- Statistik.

10. Hirtz P, Vilkner HJ (1985) Hohes Niveau koordinativer Fähigkeiten führt zu besseren Ergebnissen im motorischen Lernen. Körpererziehung 35: 151-154.
11. Hirtz P (1979) Untersuchungen zur koordinativ- motorischen Vervollkommung von Kindern und Jugendlichen. ErnstMoritz-Arndt-Universität Greifswald: Dissertation B.

12. Meinel K, Schnabel G (2015) Bewegungslehre Sportmotorik, Abriss einer Theorie der sportlichen Motorik unter pädagischen Aspekten (Vol. 12. Auflage). Aachen: Meyer\& Meyer Verlag.

13. Kircheis D (1977) Die motorische Differenzierungsfähigkeiteine wesentliche koordinative Leistungsvoraussetzung. Deutsche Hochschule für Körperkultur Leipzig: Dissertation.

14. Gonzalez V, Rowson J, Yoxall A (2017) Analyzing finger interdependencies during the Purdue Pegboard Test and comparative activities of daily living. J Hand Ther 30: 80-88.

15. Buddenberg LA, Davis C (2000) Test-retest reliability of the Purdue Pegboard Test. Am J Occup Ther 54: 555-558.

16. Ikai M (1968) Biomechanics of sprint running with respect to the speed curve. Basel, New York: Biomechanics I. Karger.

17. Bortz J, Schuster C (2010) Statistik für Human- und Sozialwissenschaftler. Berlin Heidelberg: Springer Medizin.

18. Fahrmeir L, Künstler R, Pigeot I, Tutz G (2011) Statistik Der Weg zur Datenanalyse (Vol. 7. Auflage). Heidelberg: Springer.

19. Blume DD (1978) Zu einigen wesentlichen theoretischen Grundpositionenen für die Untersuchung der koordinativen Fähigkeiten. Theorie und Praxis der Körperkultur 27: 29-36.

20. Hirtz P (2003) Koordinationstraining. In: Schnabel G, Harre D, Krug J, Borde A, Trainingswissenschaft, Berlin: Sportverlag, 272-280.

21. McGee T, Andrew J, McLaughlin K, Tanaka M, Johnson $\mathrm{K}$ (2017) Rehabilitation after medial patellofemoral ligament reconstruction. Sports Med Arthrosc Rev 25: 105-113.

22. Pracev K (1989) Die Auswahl talentierter junger Athleten. Leistungssport 6: 19-22.

23. Hermann HD (2001) Mediatoren und Modifikatoren der Belastungsreaktionen nach Sportverletzungen. Beiträge zu einem interdisziplinären Modell (Studien zur Stressforschung). Hamburg: Dr. Kovac.

24. Martin D (1982) Leistungsentwicklung und Trainierbarkeit konditioneller und koordinativer Komponenten im Kindesalter. Leistungssport 12: 14-24. 


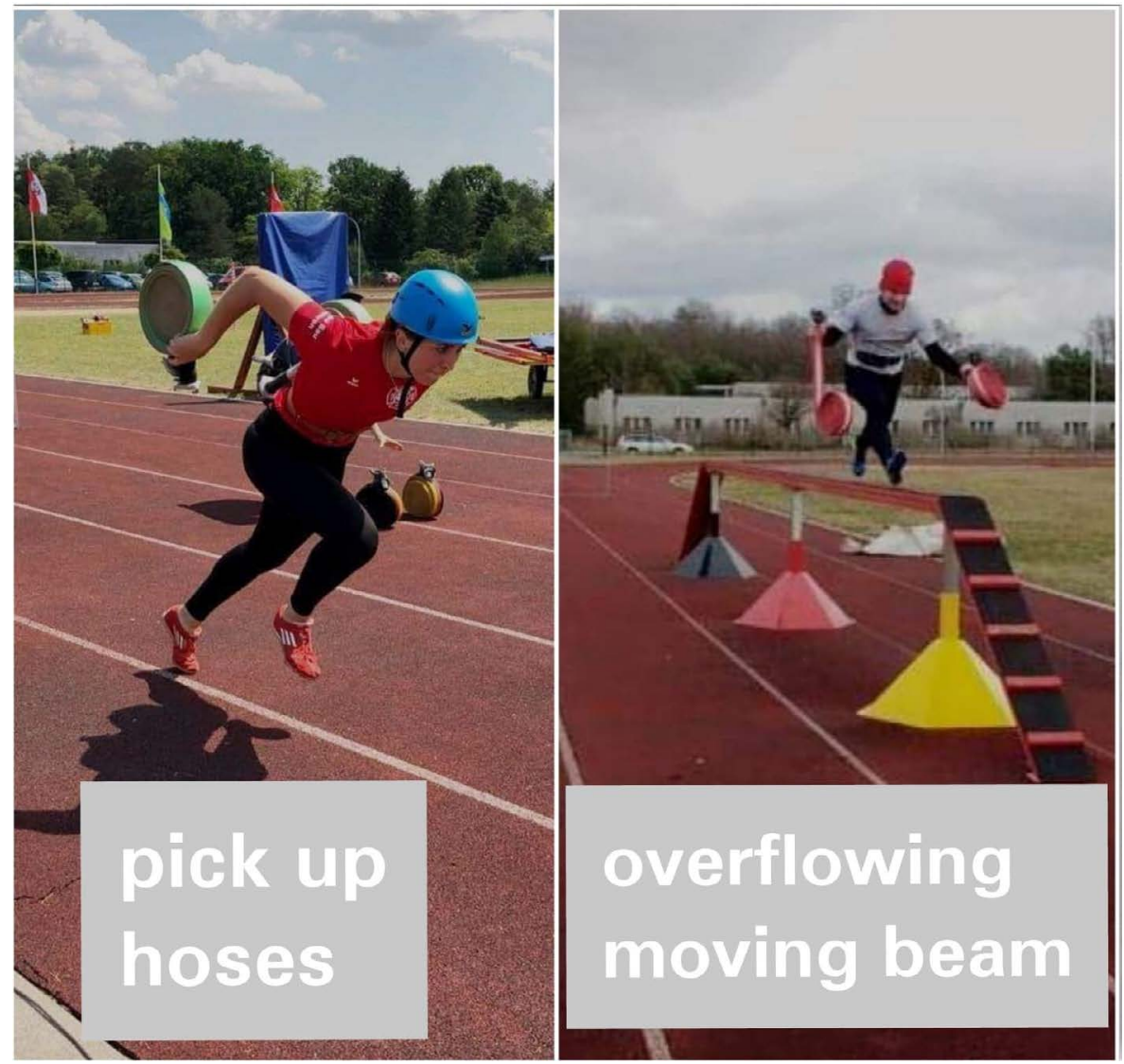

Appendix Figure 1: Impression A from the 100 m obstacle course.

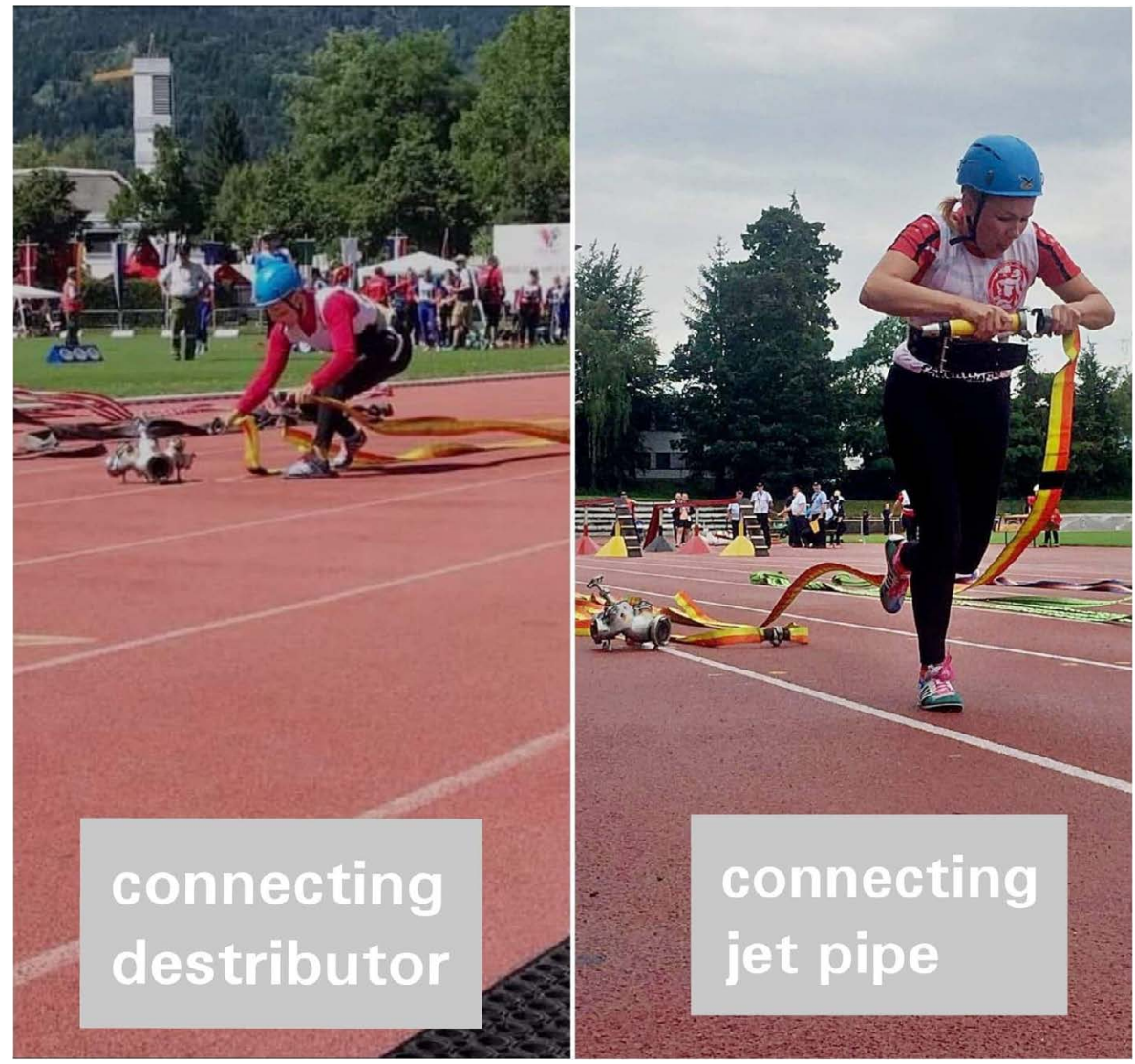

Appendix Figure 2: Impression B from the $100 \mathrm{~m}$ obstacle course. 